University of Texas Rio Grande Valley

ScholarWorks @ UTRGV

\title{
"Upregulation of STREX splice variant of the large conductance Ca2+-activated potassium (BK) channel in a rat model of mesial temporal lobe epilepsy"
}

\author{
Boris Ermolinsky \\ The University of Texas Rio Grande Valley \\ Frank Skinner \\ Ileana Garcia \\ Massoud F. Arshadmansab \\ Luis F. Pacheco Otalora
}

See next page for additional authors

Follow this and additional works at: https://scholarworks.utrgv.edu/hbs_fac

Part of the Medicine and Health Sciences Commons

\section{Recommended Citation}

Ermolinsky, B. S., Skinner, F., Garcia, I., Arshadmansab, M. F., Otalora, L. F., Zarei, M. M., \& Garrido-Sanabria, E. R. (2011). Upregulation of STREX splice variant of the large conductance Ca2+-activated potassium (BK) channel in a rat model of mesial temporal lobe epilepsy. Neuroscience research, 69(1), 73-80. https://doi.org/10.1016/j.neures.2010.09.011

This Article is brought to you for free and open access by the College of Health Professions at ScholarWorks @ UTRGV. It has been accepted for inclusion in Health \& Biomedical Sciences Faculty Publications and Presentations by an authorized administrator of ScholarWorks @ UTRGV. For more information, please contact justin.white@utrgv.edu,william.flores01@utrgv.edu. 


\section{Authors}

Boris Ermolinsky, Frank Skinner, lleana Garcia, Massoud F. Arshadmansab, Luis F. Pacheco Otalora, Masoud M. Zarei, and Emilio R. Garrido-Sanabria 


\title{
"Upregulation of STREX splice variant of the large conductance $\mathrm{Ca}^{2+-a c t i v a t e d}$ potassium $(\mathrm{BK})$ channel in a rat model of mesial temporal lobe epilepsy"
}

\author{
Boris S. Ermolinsky a,b, Frank Skinnera, lleana Garciaa ${ }^{a}$, Massoud F. Arshasamanb ${ }^{a}$, Luis \\ F. Pacheco Otalora ${ }^{a}$, Masoud M. Zarei ${ }^{a}$, and Emilio R. Garrido-Sanabria ${ }^{a, b}{ }^{*}$ \\ aDepartment of Biological Sciences at the University of Texas at Brownsville/Texas Southmost \\ College, 80 Fort Brown, Brownsville, 78520, Texas, USA
}

${ }^{\mathrm{b}}$ Center for Biomedical Studies, 80 Fort Brown, Brownsville, 78520, Texas, USA

\begin{abstract}
Functional properties of large conductance $\mathrm{Ca}^{2+}$ activated potassium (BK) channels are determined by complex alternative splicing of the Kcnmal gene encoding the alpha pore-forming subunit. Inclusion of the STREX exon in a C-terminal splice site is dynamically regulated and confers enhanced $\mathrm{Ca}^{2+}$ sensitivity and channel inhibition via cAMP-dependent phosphorylation. Here, we describe a real time quantitative PCR (qPCR) approach to investigate relative changes in the expression of STREX and ZERO splice variants using a newly designed set of probes and primers for TaqMan-based qPCR analysis of cDNA from the rat dentate gyrus at different time points following pilocarpine-induced status epilepticus. Reduction in Kcnmal gene expression is associated with a relative increase of STREX splice variant. Relative expression of STREX variant mRNA was increased at 10 days and at more than 1 month following status epilepticus. The biological consequences of seizure-related changes in alternative splicing of Kcnmal deserve additional investigation.
\end{abstract}

\section{Introduction}

Calcium $\left(\mathrm{Ca}^{2+}\right)$ and voltage activated potassium $\mathrm{K}^{+}$channels are thought to play a critical role in neuronal firing properties and circuit excitability. These channels open in response to increases in $\mathrm{Ca}^{2+}$ concentration and depolarization of the membrane potential, leading to a

\footnotetext{
(C) 2010 Elsevier Ireland Ltd and the Japan Neuroscience Society. All rights reserved.

*Corresponding author: Emilio R. Garrido Sanabria, MD, PhD, Department of Biological Sciences, 80 Fort Brown, Brownsville Texas 78520, Phone: (956) 882-5053, Fax: (956) 882-5043, emilio.garrido@utb.edu.

Publisher's Disclaimer: This is a PDF file of an unedited manuscript that has been accepted for publication. As a service to our customers we are providing this early version of the manuscript. The manuscript will undergo copyediting, typesetting, and review of the resulting proof before it is published in its final citable form. Please note that during the production process errors may be discovered which could affect the content, and all legal disclaimers that apply to the journal pertain.

Referee suggestions

Okamoto K, Laboratório de Neurociência, Disciplina de Neurologia Experimental, Universidade Federal de São Paulo, Rua Botucatu 862, Ed Leal Prado CEP-04023-900, São Paulo, Brazil. keith.nexp@epm.br.

Naruse K, Department of Cardiovascular Physiology, Okayama University Graduate School of Medicine, Dentistry and

Pharmaceutical Sciences, 2-5-1 Shikata-cho, Kita-ku, Okayama 700-8558, Japan knaruse@ md.okayama-u.ac.jp

Toro L. Dept. Anesthesiology, UCLA, BH-509A CHS, Box 957115, Los Angeles, CA 90095-7115, USA. 1toro@ucla.edu.

F. Edward Dudek. Department of Physiology, University of Utah School of Medicine 420 Chipeta Way, Suite 1700, Salt Lake City, Utah 84108-6500, ed.dudek@hsc.utah.edu

Grosso S. Department of Pediatrics, Pediatric Neurology Section, University of Siena, Viale M. Bracci, Le Scotte, Siena, Italy. grosso@unisi.it
} 
secondary hyperpolarization that may reestablish membrane potential and $\mathrm{Ca}^{2+}$ levels, or even produce afterhyperpolarization to potentials more negative than the resting membrane potential (Calderone, 2002; Kaczorowski et al., 1996; Latorre and Brauchi, 2006; Latorre et al., 1989; McManus, 1991; Nardi and Olesen, 2008; Sah and Faber, 2002; Stocker et al., 2004; Weiger et al., 2002). Accordingly, these channels have been considered to play an important modulatory role in presynaptic release of glutamate (e.g. feedback "break" on excitation) during periods of enhanced excitability including seizures (Empson and Jefferys, 2001; Hu et al., 2001; Lu et al., 2006; Martin et al., 2001; Shanley et al., 2002). However, it was recently discovered that an abnormal increase in the BK channel conductance, caused by a "gain-of-function" mutation in the large-conductance $\mathrm{Ca}^{2+}$ and voltage gated $\mathrm{K}^{+}$ channel (i.e. BK, MaxiK, Slo) $\alpha$-subunit (Kcnmal gene), underlies human epilepsy and paroxysmal movement disorder (Du et al., 2005). The putative mechanism responsible for this pro-epileptic action is associated with BK channel-mediated increase in high-frequency firing (Brenner et al., 2005; Gu et al., 2007; Shruti et al., 2008; Wang et al., 2009). In CA1 pyramidal cells, BK channel activation induces rapid spike repolarization and fast afterhyperpolarization, which in turn limits activation of slower $\mathrm{K}^{+}$channels (in particular the delayed rectifier potassium current $\left.\left(I_{\mathrm{DR}}\right)\right)$ and $\mathrm{Na}^{+}$channel inactivation, leading to highfrequency firing (Gu et al., 2007). Moreover, mice lacking the $\beta 4$ BK channel subunit exhibit a "gain-of-function" for BK channels that sharpen action potentials in dentate granule neurons, thereby facilitating high-frequency firing and leading to temporal lobe seizures (Brenner et al., 2005). Hence, augmentation in this particular $\mathrm{K}^{+}$conductance is considered to paradoxically mediate network hyperexcitability and seizures (Wang et al., 2009). Interestingly, expression of BK channels is downregulated in the pilocarpine model of mesial temporal lobe epilepsy (MTLE) (Ermolinsky et al., 2008a; Xie and McCobb, 1998 (Ermolinsky et al., 2008a,Pacheco Otalora et al., 2008), indicating a possible seizure-related disturbance of BK channel transcriptional mechanisms.

It remains unclear whether defective BK channel expression in MTLE is associated with abnormal post-translational processing of transcripts, RNA post-transcriptional editing, and/ or alternative splicing. Alternative splicing can dramatically modify the functional properties of BK channels, including $\mathrm{Ca}^{2+}$ and voltage sensitivity, cell surface expression, and regulation by diverse intracellular signaing pathways. For intance, BK channel pore-forming $\alpha$-subunits are encoded by a single gene, Kcnmal, which undergoes extensive alternative pre mRNA splicing. Insertion of the 58 amino acid (STRess axis-regulated) EXon (STREX) in a $\mathrm{C}$-terminal splice site encodes channels with distinct functional phenotypes (i.e. altered $\mathrm{Ca}^{2+}$ sensitivity and regulation by diverse signaling pathways such as cAMP-activated kinase phosphorylation) compared to the insertless (ZERO) variant (Chen et al., 2005; MacDonald et al., 2006; Petrik and Brenner, 2007; Shipston et al., 1999; Tian et al., 2001a; Tian et al., 2001b; Xie and McCobb, 1998). Thus, expression of distinct splice variants has been proposed as an important mechanism to differentially shape neuronal electrical properties and may play a critical role in epileptogenesis. In mammals, splicing of the STREX exon is developmentally regulated (MacDonald et al., 2006) and dynamically controlled by cellular excitability, as well as circulating stress and sex hormones (Erxleben et al., 2002; Lai and McCobb, 2002, 2006; Mahmoud and McCobb, 2004; McCartney et al., 2005; McCobb et al., 2003; Shipston et al., 1999; Tian et al., 2003; Tian et al., 2001a; Tian et al., 2001b; Xie and Black, 2001; Xie and McCobb, 1998;Zhu et al., 2005). Accordingly, post-transcriptional BK channel splicing may be abnormally regulated during periods of enhanced excitability in epilepsy. In this manuscript, we use the comparative cycle threshold (CT) method, also known as the delta-delta $(\Delta \Delta) \mathrm{CT}$ of the quantitative real-time polymerase chain reaction (qPCR) technique, using TaqMan ${ }^{\mathrm{TM}}$ hydrolysis probes for the analysis of seizure-related changes in BK channel STREX and ZERO splice variant expression, and to test the hypothesis that alternative splicing BK channel is dynamically regulated during different periods of epileptogenesis in a rat model of MTLE. 


\section{Material and Methods}

\section{Animals and rat model of chronic epilepsy}

All experiments were performed in accordance with the National Institutes of Health Guidelines for the Care and Use of Laboratory Animals and with the approval of The University of Texas at Brownsville Institutional Animal Care and Use Committee (IACUC). Wistar rats were kept in IACUC-certified vivarium with water and food ad libitum. Chronic epileptic rats were obtained by the Cavalheiro's model of temporal lobe epilepsy (Cavalheiro, 1995; Cavalheiro et al., 1991; Turski et al., 1983). At the time of performing the model of epilepsy, animals were approximately $31-45$ days. Pilocarpine was administered between 9 A.M. and 12 A.M in an acclimatized room set at 20oC. All animals received the same dose of $1 \%$ methyl-scopolamine nitrate $(0.1 \mathrm{mg} / \mathrm{kg}$ in saline, s.c.) (SigmaAldrich, St. Louis, MO) thirty minutes before pilocarpine administration to minimize the peripheral effects of cholinergic stimulation (Turski et al., 1984). Animals were then injected with $4 \%$ pilocarpine hydrochloride (Sigma-Aldrich) $(350 \mathrm{mg} / \mathrm{kg}$ in saline, i.p.). Controls included (a) animals that received methyl-scopolamine but were injected with saline instead of pilocarpine, (b) saline-injected control animals that also received diazepam. Systemic pilocarpine injection induced status epilepticus (SE) in 70\% of injected rats, consisting of continuous tremor, rearing, myoclonic jerks, clonic forearms, brief tonic seizures and head movements with eventual side fallings. The intensity of motor seizures was apparently similar across animals entering SE. Only animals that experienced at least 3 hours of self-sustained SE were included in this study. The mortality rate was minimized by administering diazepam $(10 \mathrm{mg} / \mathrm{kg}$, i.p. $)$ at 3 hours of SE onset to quell behavioral seizures (Ermolinsky et al., 2008a; Garrido-Sanabria et al., 2008; Pacheco Otalora et al., 2008). All animals that received pilocarpine were given fresh apples and water in an easily reachable container inside the recovery cage 48 hours after SE induction. Two subcutaneous injections of $20 \mathrm{ml}$ Ringer-lactate was administered 4 hours following SE onset and on the next day to compensate for any liquid lost (i.e. salivation, urination). SE induction protocol was lethal in about $15-20 \%$ of pilocarpine-treated rats. After SE, rats were monitored for detection of at least two spontaneous seizures using a JVC MiniDV digital video-camera and researcherassisted SeizureScan software suite (Clever Sys., Inc, Reston, VA) and by an experienced research staff to define the beginning of the chronic phase (on average 2-3 weeks after SE induction). Only seizures graded $\geq 3$ in the Racine's scale (Racine, 1972) were computed (according to maximal sensitivity of the detection system). On average, SE-suffering rats experienced approximately 5-8 seizures per week regularly during the observation period.

\section{RNA isolation, reverse transcription and real-time quantitative PCR}

The methodology and terms used throughout the manuscript are in accordance with the "The Minimum Information for Publication of Quantitative Real-Time PCR Experiments" (MIQE) guidelines (Bustin et al., 2009). In order to analyze SE-induced changes in splicing of BK $\alpha$ subunit channels in dentate gyrus, a library of cDNA was obtained from animals sacrificed at different time periods following the induction of SE. The dentate gyrus was selected due to: (a) the predominant expression of BK channels in the axons (mossy fibers) of granule cells, and (b) the resistance of granule cells to SE-induced cell injury. Conspicuous cell loss and injury of the pyramidal cell layer in the pilocarpine model of epilepsy (Cavalheiro, 1995; Cavalheiro et al., 1991; Turski et al., 1983) may introduce potential technical pitfalls on the normalization of the cDNA and interpretation of results. Accordingly, for isolation of total RNA, pilocarpine-treated rats were anaesthetized and sacrificed at 1 day, 10 days, 1 month, and at more than 2 months (late chronic period) after induction of SE. Total RNA isolation from microdissected dentate gyrus was performed as reported earlier (Ermolinsky et al., 2008a; Ermolinsky et al., 2008b; Pacheco Otalora et al., 2008). Tissue was collected, weighed (about $20 \mathrm{mg}$ ), homogenized, and processed for total 
RNA isolation at $4^{\circ} \mathrm{C}$ using the RNAqueous-4PCR Kit (Applied Biosystems, Inc, ABI, Foster City, California, USA) following the manufacturer's instructions. The concentration and purity of RNA for each sample was determined by UV absorbance using an ND-1000 spectrophotometer (Nanodrop, Fisher Thermo, Wilmington, DE, USA). Traces of genomic DNA were minimized by DNAse treatment (DNA-free ${ }^{\mathrm{TM}}$ DNase Treatment \& Removal Reagents and TURBO DNA-free kit, Ambion, ABI) of the samples. The final concentration of RNA was then measured and samples were stored at $-80^{\circ} \mathrm{C}$ until conversion to cDNA. The integrity of the extracted RNA was confirmed by electrophoresis under denaturating conditions. RNA samples from each set of control and epileptic rats were processed in parallel under the same conditions. RT reactions were performed on an iCycler Thermal Cycler PCR System (Bio-Rad Laboratories, Hercules, California, USA), using the High Capacity cDNA Reverse Transcription Kit (P/N: 4368814; Applied Biosystems, ABI, California, USA) for synthesis of single-stranded cDNA. The cDNA synthesis was carried out by following manufacturer's protocol using random primers for $1000 \mathrm{ng}$ of starting total RNA. The efficiency of the RT reaction was determined by analysis of serial dilutions of input RNA. Each RNA concentration was reverse transcribed using the same RT reaction volume. The resulting cDNA template from each sample was subjected to qPCR analysis. Real-time PCR was performed at the StepOne Real-Time PCR System (ABI) using self designed TaqMan hydrolysis probes (STREX and ZERO), TaqMan-based ABI gene expression assays Rn99999916_s1 (Gapdh) and Rn01268575_m1 (Kcnmal). The qPCR was performed in triplicate on cDNA samples or oligonucleotide standards in a MicroAmp Optical 48-well reaction plate (ABI) covered by MicroAmp 48-well Optical Adhesive Film (ABI). Reaction volume standard well contained $20 \mu \mathrm{l}$ : $10 \mu \mathrm{l}$ of TaqMan Universal PCR Master Mix (ABI), $1 \mu \mathrm{l}$ of 20x TaqMan assay, $8 \mu \mathrm{l}$ of water and $1 \mu \mathrm{l}$ of analyzed sample. Self designed 20x assays (STREX and ZERO) contained $16 \mu \mathrm{M}$ of each forward and reverse primers and $5 \mu \mathrm{M}$ of TaqMan probe. The final PCR conditions were as follows: pre-heating at $50^{\circ} \mathrm{C}$ for $2 \mathrm{~min}$, denaturation at $95^{\circ} \mathrm{C}$ for $10 \mathrm{~min}$ and 40 cycles of amplification and quantification $\left(15 \mathrm{~s}\right.$ at $95^{\circ} \mathrm{C}$ and $60 \mathrm{~s}$ at $\left.60^{\circ} \mathrm{C}\right)$.

For reference (normalizing) gene we used validated Taqman-based ABI gene expression assay Rn99999916_s1 gene Glyceraldehyde 3-phosphate dehydrogenase (Gapdh) (amplicon size $=87 \mathrm{bp}$ ) of Rattus norvegicus. Usually, plates contained cDNA from calibrator sample, and 2 to 3 control and 2 to 3 experimental (epileptic) samples in triplicates. In the previous study, we demonstrated that Gapdh levels are relatively unchanged across all experimental time points following SE, hence this normalization gene was suitable to investigate relative changes in gene expression in epilepsy (Ermolinsky et al., 2008b). For analysis, data from both control groups were pooled together since no significant changes were observed in relative expression of Kcnmal, STREX or ZERO. We investigated relative changes in the main Kcnmal transcript and the splice variants STREX and ZERO. Kcnmal gene mRNA expression was measured using a StepOne Real-Time PCR System using the validated TaqMan Gene Expression Assays Rn01268575_m1 for target gene Kcnmal (RefSeq: NM_031828.1) (amplicon size $=108 \mathrm{bp}$, assay location 874). The location of the Kcnmal TaqMan assay is at least 1725 bp downstream from the STREX splicing C2 site.

\section{TaqMan probes for STREX and ZERO splice variants of KCNMA1 gene}

Sequence information for designing STREX and ZERO splice variant primers and probes was obtained from previous works (Shipston et al., 1999; Xie and McCobb, 1998; Zhu et al., 2005). For this project, STREX is a transcript variant with the insert of 174 bp STREX exon while ZERO means the absence (insertless) of the STREX exon as previously described (Figure 1) (Xie and McCobb, 1998). TaqMan ${ }^{\mathrm{TM}}$ probes, labelled at the 5' end with FAM (6carboxyfluorescein) and at the 3' end with TAMRA (6-carboxytetramethylrhodamine), were synthesized by Applied Biosystems. Primers and probes for TaqMan hydrolysis qPCR 
assays, specific for each splice variant, were designed using the Primer Express v3.0 program (ABI). For STREX (Table 1), the forward (5'- AGCCGAGCATGTTGTTTTGAT $\left.-3^{\prime}\right)$ and reverse (5'- ACGCACACGGCCTGACA $-3^{\prime}$ ) primer sequences amplify a 69 base pair region of the STREX (STREX-1+STREX-2) variant of $\mathrm{Ca}^{2+}$-activated potassium channel, subfamily M subunit $\alpha-1$ genome (Genbank GeneID: 83731), and probe (5'-FAMCGTTCTGAGCGTGACTGCTCGTGC -TAMRA-3') (Xie and McCobb, 1998) (Figure 1B, Table 1). For ZERO (Table 1), the forward (5'-TGTCATGATGACGTCACAGATCC -3') and reverse ( $5^{\prime}$ - TTTTTTTGGTGACAGTGTTGGC $-3^{\prime}$ ) primer sequences amplify a 92 base pair region of the Zero variant of $\mathrm{Ca}^{2+}$-activated potassium channel, subfamily $\mathrm{M}$ subunit $\alpha-1$ genome (Genbank GeneID: 83731), and probe (5'-FAMTTGCTCATCTTCAAGCCGCCTGC -TAMRA-3') to span exon junctions (Xie and McCobb, 1998). Duplex formation and secondary nucleic acid structures of primer sequences were rechecked using OligoAnalyzer 3.0 (Integrated DNA Technologies). Upon BLAST search (http://blast.ncbi.nlm.nih.gov/), primer and probe sequences did not show significant sequence homology to any non-rat available DNA sequence. In addition, primers were checked for ability to amplify nonspecific regions from human DNA sequences using Primer-Blast (http://blast.ncbi.nlm.nih.gov/). The analysis of primers performed by PrimerBlast throughout all rat DNA sequences in NCBI showed only one specific product.

For assessing efficiency of probes in the assays, a logarithmic dilution of synthesized oligonucleotides was prepared and samples run in triplicate. For this purpose, amplicon oligonucleotides corresponding to the amplicons (positive controls) obtained with the ZERO and STREX primers were synthesized by IDT Technologies (Coralville, IA, USA), quantified, converted to number of molecules and diluted to assess efficiency of assays (Supplemental Material, e-components). From the amplification curves, CT $\left(\mathrm{C}_{\mathrm{q}}\right)$ values for each concentration were determined and the slope of CT $v s . \log$ [cDNA] was used to calculate the efficiency of amplification (using StepOne software, ABI). TaqMan ${ }^{\mathrm{TM}}$ assay was linear at 7 orders of magnitude and the efficiency-correlation coefficient $\left(\mathrm{R}^{2}\right)$ determined from 2 independent experiments. To determine specificity of the BK splice variant assays, standard curves were also generated for each variant in the presence of a competing concentration of another variant (synthetic amplicons were synthesized by Integrated DNA Technologies, Inc) for either STREX or ZERO variants. In each case no competition was observed in the presence of 10,000 fold excess of the respective competing variant as follows: STREX TaqMan assay (STREX amplicons $+10,000$ fold ZERO amplicon, slope $=-3.238, R^{2}=0.997$, efficiency $=103.6$ compared to slope $=-3.273, R^{2}=1$, efficiency=- 102.1 for only input STREX amplicons) and ZERO TaqMan assay (ZERO amplicons $+10,000$ fold STREX amplicon, slope $=-3.349, \mathrm{R}^{2}=0.996$, efficiency $=98.8$ compared to slope $=-3.187, \mathrm{R}^{2}=0.999$, efficiency $=-102.9$ for only input $\mathrm{ZERO}$ amplicons).

In a separate validation experiment for checking ability to use $\Delta \Delta \mathrm{CT}$ method, standard curves were prepared for serial dilutions of input cDNA for STREX, ZERO and Gapdh. The dilution series of cDNA containing the target gene of interest were analyzed by qPCR. The slopes of the dilution series were calculated by determining $\triangle \mathrm{CT}$ between each point on the dilution series plotted against the log of sample (cDNA) input (mass). The rationale is that for performing $\Delta \Delta \mathrm{CT}$ analysis no change or a very small difference in efficiencies should exist between the gene of interest and the endogenous control (i.e. Gapdh) in the assays (Pfaffl, 2001). For each of these assays, efficiency and $\mathrm{R}^{2}$ was appropriate (Supplemental Material, e-components) and slope of the line for $\Delta \mathrm{CT}$ of Gapdh and targets (STREX and ZERO) was less than 0.1 respectively (Supplemental Material, e-components).

For qPCR analysis, each sample was run in triplicates. Each run included a no template control to test for contamination of assay reagents. After a $94^{\circ} \mathrm{C}$ denaturation for $10 \mathrm{~min}$, reactions were cycled 40 times with a $94^{\circ} \mathrm{C}$ denaturation for $15 \mathrm{~s}$, and a $60^{\circ} \mathrm{C}$ annealing for 1 
min. Three types of controls aimed at detecting genomic DNA contamination in the RNA sample or during the RT or qPCR reactions were always included: a RT mixture without reverse transcriptase, a RT mixture including the enzyme but no RNA, negative control (reaction mixture without cDNA template). The data were collected and analyzed using OneStep Software (ABI). Relative quantification was performed using the comparative threshold (CT) method after determining the CT values for reference (Gapdh) and target (Kcnmal) genes in each sample sets according to the $\Delta \Delta \mathrm{CT}$ method (delta-delta $\mathrm{CT}$ ) as described by the manufacturer (ABI; User Bulletin 2). Changes in mRNA expression level were calculated after normalization to Gapdh. As calibrator sample, we used cDNA from an arbitrarily selected control rat brain. The $\Delta \Delta \mathrm{CT}$ method provides a relative quantification ratio according to the calibrator that allows statistical comparisons of gene expression among samples. Values of fold changes in the control sample versus the post-SE samples represent averages from triplicate measurements. Changes in gene expression were reported as fold changes relative to controls. Data were analyzed by analysis of variance (ANOVA) (followed by post-hoc analysis) or via paired $t$-test to check for statistically significant differences among the groups (significance $P$ value was set at $<0.05$ ).

\section{Results}

We tested the hypothesis that seizures and chronic epilepsy are associated with a dysregulation of Kcnmal gene splicing for the pore forming subunit of BK channels. For this purpose, we designed qPCR assays using custom made TaqMan probes to detect changes in gene expression of the main splice variants of BK channels STREX and ZERO. Total BK channel (Kcnmal) expression was measured using the validated TaqMan Gene Expression Assays Rn01268575_m1 for target gene Kcnmal (RefSeq: NM_031828.1) and Rn99999916_s1 for the internal normalization gene Gapdh. Analysis was performed on total RNA extracted from dentate gyrus of two experimental groups including control (saline injected non-epileptic rats, $\mathrm{n}=6$ ) and rats sacrificed at different time points after status epilepticus as follows: 1 day $(\mathrm{n}=6), 10$ days $(\mathrm{n}=5), 1$ month $(\mathrm{n}=5)$, more than 2 months $(n=6)$. Statistical analysis revealed a significant change in expression of the three transcripts for each set of experimental groups using analysis of variance (one-way ANOVA) with significance at $\mathrm{P}<0.05$ (Table 2). Post-hoc comparisons via the Tukey Honest Significant Difference (HSD) test for Kcnmal gene expression analysis revealed a significant reduction of transcripts at 1 day (34.6\% reduction), 10 days (66.1\% reduction), 1 month (79.4\% reduction) and more than 2 months (67.5\% reduction) following $\mathrm{SE}(\mathrm{P}<0.05, \mathrm{P}<0.05$, $\mathrm{P}<0.01, \mathrm{P}<0.05$ respectively) compared to control (Table 2 ). In addition, a significant reduction was also detected for the group of 1 month when compared to 1 day, 10 days, and more than 2 months after SE ( $\mathrm{P}<0.05$ in all cases, Tukey HSD post-hoc test). A partial recovery of gene expression was observed after 2 months. Post-hoc analysis for ZERO exhibited a similar pattern as Kcnmal gene expression following pilocarpine-induced SE. Accordingly, ZERO expression was significantly reduced at 1 day (50\% reduction), 10 days (68.1\% reduction), 1 month (85.3\% reduction) and at more than 2 months after SE (73.6\% reduction) $(\mathrm{P}<0.05, \mathrm{P}<0.01, \mathrm{P}<0.001, \mathrm{P}<0.05$ respectively compared to controls). The maximal reduction of ZERO transcripts was observed at 1 month following SE. Such downregulation was significant compared to 1 day $(\mathrm{P}<0.001), 10$ days $(\mathrm{P}<0.05)$ and at more than 2 months $(\mathrm{P}<0.05)$ (Tukey HSD post-hoc comparisons). No significant difference was noted between 1 day, 10 days and more than 2 months following SE.

In contrast, STREX transcript expression pattern exhibited some dissimilarities to Kcnmal and ZERO. Although a significant 54.3\% reduction (Tukey HSD, P<0.05) was observed for STREX transcripts compared to controls, expression at 10 days following SE significantly increased $28 \%$ above control values ( $\mathrm{p}<0.05$, Tukey HSD post-hoc) and $82.8 \%$ more ( $\mathrm{p}<0.001$, Tukey HSD post-hoc) than 1 day following SE. The expression of STREX then 
significantly reduced $65.9 \%$ less than controls ( $\mathrm{p}<0.01$, Tukey HSD post-hoc) and partially recovered at more than 2 months following $\mathrm{SE}$ (36.7\% reduction, $\mathrm{P}<0.01$ compared to controls and $\mathrm{P}<0.05$ compared to the 1 month period).

To further illustrate the difference in expression patterns for ZERO and STREX transcripts, we compared the percentage change relative to the Kcnmal expression levels at 1 day, 10 days, 1 month and more than 2 months following pilocarpine-induced SE. After an initial decline of STREX splice variants, significant increases were detected at 10 days, 1 month and 2 months following SE when compared to control and 1 day groups respectively (Figure $2 \mathrm{~A})$. The highest levels were detected at 10 days following $\mathrm{SE}$ and then significant $45.8 \%$ and $51.3 \%$ reductions were observed at 1 month and 2 months compared to 10 days after SE ( $\mathrm{P}<0.01$ in both cases by Tukey HSD post-hoc analysis). The analysis of STREX/ZERO relative ratios at different time points indicates a proportional increase on STREX variant after 10 days following pilocarpine-induced SE (Figure 2B). In addition, representation of data as a proportional change of Kcnmal main transcript (Figure 2C) revealed a significant increase on the relative STREX/Kcnmal expression at 10 days (445.1\%), 1 month (204.8\%) and more than 2 months after SE (228.4\%) when compared to 117.5\% STREX/Kcnmal ratio in control group (ANOVA, $\mathrm{P}<0.001$ ) while minimal changes were observed in ZERO/ Kcnmal proportions.

\section{Discussion}

In previous work, we have reported a down-regulation of Kcnmal main transcripts and corresponding protein expression in the pilocarpine model of MTLE (Ermolinsky et al., 2008a; Pacheco Otalora et al., 2008). Here, we further explored whether reduction in BK channel expression is also accompanied by changes in alternative splicing, specifically for the main splice variant STREX, as characterized by TaqMan-based qPCR. Our data indicate that the consistent reduction of Kcnmal main transcript expression is accompanied by a down-regulation of ZERO splice variant and a significant relative increase in the expression of STREX in chronic epileptic animals specifically at 10 days and more than 2 months following SE. The mechanism and functional impact of these complex changes are matters of speculation. Expression of STREX splice variant has been reported to be around 5\% in the adult brain (MacDonald et al., 2006). Hence, significant increases in relative expression of STREX during epileptogenesis may result in profound changes in neuronal excitability in epilepsy. Further experiments are required to decipher the functional implications of changes in STREX expression for the pathogenesis of epilepsy.

Insertion of the 58 amino acid STress-Regulated Exon (STREX), which is conserved throughout vertebrate evolution, encodes channels with distinct $\mathrm{Ca}^{2+}$ sensitivity and regulation by diverse signaling pathways, compared to the insertless (ZERO) variant (Lai and McCobb, 2006; MacDonald et al., 2006; McCobb et al., 2003; Petrik and Brenner, 2007; Shipston et al., 1999; Tian et al., 2001b; Xie and McCobb, 1998). The interaction of $\mathrm{Ca}^{2+}$ and STREX splicing is quite complex. For example, inclusion of the STREX exon increases the BK channel sensitivity to stimulation by $\mathrm{Ca}^{2+}$ (Erxleben et al., 2002). Since expression of BK channels is reduced in chronically epileptic rats, we hypothesize that enhanced $\mathrm{Ca}^{2+}$ sensitivity may increase activation of remaining channels as a way to ameliorate neuronal hyperexcitability. Further studies are needed to investigate this putative compensatory mechanism in MTLE.

Although absolute qPCR quantification was not performed in this study, increase in the proportion of STREX variant relative to Kcnmal and ZERO may indicate change in the absolute number of transcripts. In adult normal brain, STREX represent about 5\% of total Kcnmal transcripts (MacDonald et al., 2006). Moreover, splicing variant transcripts may be 
processed in different ways or translated with different efficiencies. Further studies are necessary to elucidate actual changes in the absolute number of STREX variant, and to determine the relevance of these changes for the pathogenesis of epilepsy. In addition, STREX channels were shown to open more easily than ZERO channels (Saito et al., 1997; Xie and McCobb, 1998). Hence, it is possible that relative up-regulation of STREX channels in the hippocampus of epileptic rats may be part of compensatory changes to offset the reduction of main Kcnmal transcripts.

It was previously reported that total BK channel transcripts up-regulation throughout the murine CNS during embryonic and postnatal development is associated with a decrease in STREX variant mRNA expression and an up-regulation in ZERO variant expression (MacDonald et al., 2006). These authors proposed that as BK channel splice variants encode channels with distinct functional properties, the switch in splicing from the STREX phenotype to ZERO phenotype during embryonic and postnatal CNS development may provide a mechanism to allow BK channels to control distinct functions at different times of mammalian brain development (Chen et al., 2005; MacDonald et al., 2006). Similarly, changes in relative expression of STREX and ZERO in epileptogenesis may trigger compensatory modifications of neuronal excitability. It has been demonstrated that STREX channel properties promote repetitive firing by speeding action potential repolarization and augmenting the afterhyperpolarization, facilitating $\mathrm{Na}^{+}$channel de-inactivation (Xie and McCobb, 1998). Thus, by modulating the splicing pattern, neurons may modify intrinsic properties, as postulated for the action of glucocorticoids on tuning the intrinsic excitability of chromaffin cells to increase their ability to rapidly secrete epinephrine under provocation (Lovell et al., 2004; Xie and McCobb, 1998).

The rat adrenal hormone corticosterone binds to low and high affinity receptors, discretely localized in the brain, including the dentate gyrus. Differential activation of the two receptor types under physiological conditions alters gene expression and functional characteristics of hippocampal neurons (Qin et al., 2004). Dentate granule cells are enriched with receptors for the stress hormone corticosterone, i.e., the high-affinity mineralocorticoid receptor, which is already extensively occupied with low levels of the hormone, and the glucocorticoid receptor, which is particularly activated after stress(Joels, 2007; Montaron et al., 2003). These hormones are considered to regulate hippocampal (specifically dentate gyrus) plasticity (Bartolomucci et al., 2002; Fuchs and Flugge, 1998; Fuchs et al., 2001; McEwen, 2000, 2001; Ormerod et al., 2003; Takahashi, 1996). For instance, in the absence of corticosteroids, proliferation and apoptotic cell death are dramatically enhanced. Dendritic morphology and synaptic transmission are compromised (Joels, 2007). Conversely, prolonged exposure of animals to a high level of corticosterone suppresses neurogenesis and presumably makes dentate granule cells more vulnerable to delayed cell death (Huang and Herbert, 2006; McEwen, 2000; Mirescu and Gould, 2006; Radley and Morrison, 2005). These corticosteroid effects on dentate cell and network function are translated into behavioral consequences in health and disease. Stress and associated hormonal dysregulations have been described in epilepsy. For instance, it has been previously reported that plasma ACTH increases after seizures and is accompanied by a later increase in plasma cortisol in epileptic patients (Aminoff et al., 1984). Furthermore, a compelling number of studies indicate a dysregulation of the Hypothalamus-Pituitary axis in pilocarpine-treated epileptic rats. Furthermore, interictal elevation of plasma corticosterone has been detected following experimental seizures in rats (Mazarati et al., 2009a; Mazarati et al., 2009b). Specifically, the radioimmunoassay study has demonstrated elevated levels of plasma corticosterone (CORT), exacerbated and prolonged increase of CORT in response to corticotropin-releasing hormone (CRH), and failure of dexamethasone to suppress CORT (Mazarati et al., 2009a). Since alternative splicing changes in the ratio of STREX/ZERO has been related to stress, cortisol levels and stress-like manipulations, it is possible that seizure- 
induced stress in chronically epileptic rats may critically modify gene expression and alternative splicing of Kcnmal at C2 splicing site.

\section{Conclusions}

The exact role of BK channels in epilepsy is not yet established. It is possible that downregulation of BK channels may exert a compensatory role, depending on the subcellular location and expression in specific neuronal subtypes and compartments. For instance, gainof-function of BK channels has been related to familial human epilepsy and experimental seizures (Brenner et al., 2005; Sheehan et al., 2009; Shruti et al., 2008). Interestingly, BK channels are strategically expressed at presynaptic sites in the mossy fiber pathway of the hippocampus, where they may govern transmitter release (Knaus et al., 1996; Pacheco Otalora et al., 2008). Speculatively, increased expression of STREX splice variant may act as a "gain-of-function" transcriptional mechanism that may tend to restore function (e.g. cAMP-mediated phosphorylation) of overall number of down-regulated BK channels in MTLE. Functional implications of seizure-induced Kcnmal gene expression downregulation and aberrant alternative splicing for STREX and ZERO remain to be determined in the pilocarpine model of temporal lobe epilepsy.

\section{Research Highlights}

- Kcnma1 main transcript is down-regulated after status epilepticus

- Abnormal splicing of Kcnmal transcript was detected in epilepsy

- Relative increase of STREX splice variant following status epilepticus

\section{Supplementary Material}

Refer to Web version on PubMed Central for supplementary material.

\section{Abbreviations}

BK

cAMP

$\mathrm{Ca}^{2+}$

CA1

CT

$\mathbf{C}_{\mathbf{q}}$

$\Delta \mathrm{CT}=\Delta \mathrm{C}_{\mathrm{q}}$

$\Delta \Delta \mathrm{CT}$

$\Delta \Delta \mathbf{C q}$

DG

Kcnmal
Large conductance calcium- and voltage activated potassium channel

Cyclic Adenosine Monophosphate

Calcium

Corpus Ammonis Area 1

Cycle Threshold (Quantification Cycle $)=\mathrm{C}_{\mathrm{q}}$

Cycle Threshold (Quantification Cycle)

Delta Cycle Threshold method of comparative real time PCR

Delta-Delta Cycle Threshold method of comparative real time PCR

Delta-Delta Quantification Cycle

Dentate Gyrus

Gene coding for pore-forming alpha subunit of large conductance calciumactivated potassium channel

qPCR

Quantitative real time polymerase chain reaction

MaxiK

Large conductance calcium- and voltage-activated potassium channel

Mesial Temporal Lobe Epilepsy 
SE

Slo

STREX

ZERO
Status Epilepticus

Large conductance $\mathrm{Ca}^{2+}$-and voltage activated potassium channel

STRess axis-regulated EXon of Kcnmal

Insertless splice variant of Kcnmal

\section{Acknowledgments}

This work was supported by grants to E.R.G.S from National Institute of Health as follows: NS063950-03, P20MD001091, P20MD000161, 5SC1NS063950-04, MBRS-RISE grant \#1R25GM06592501A1 and ARRA grant 3SC1NS063950-03S1.

\section{References}

Aminoff MJ, Simon RP, Wiedemann E. The hormonal responses to generalized tonic-clonic seizures. Brain 1984;107(Pt 2):569-578. [PubMed: 6144354]

Bartolomucci A, de Biurrun G, Czeh B, van Kampen M, Fuchs E. Selective enhancement of spatial learning under chronic psychosocial stress. Eur J Neurosci 2002;15:1863-1866. [PubMed: 12081667]

Brenner R, Chen QH, Vilaythong A, Toney GM, Noebels JL, Aldrich RW. BK channel beta4 subunit reduces dentate gyrus excitability and protects against temporal lobe seizures. Nat Neurosci 2005;8:1752-1759. [PubMed: 16261134]

Bustin SA, Benes V, Garson JA, Hellemans J, Huggett J, Kubista M, Mueller R, Nolan T, Pfaffl MW, Shipley GL, Vandesompele J, Wittwer CT. The MIQE guidelines: minimum information for publication of quantitative real-time PCR experiments. Clin Chem 2009;55:611-622. [PubMed: 19246619]

Calderone V. Large-conductance, ca(2+)-activated k(+) channels: function, pharmacology and drugs. Curr Med Chem 2002;9:1385-1395. [PubMed: 12132994]

Cavalheiro EA. The pilocarpine model of epilepsy. Ital J Neurol Sci 1995;16:33-37. [PubMed: 7642349]

Cavalheiro EA, Leite JP, Bortolotto ZA, Turski WA, Ikonomidou C, Turski L. Long-term effects of pilocarpine in rats: structural damage of the brain triggers kindling and spontaneous recurrent seizures. Epilepsia 1991;32:778-782. [PubMed: 1743148]

Chen L, Tian L, MacDonald SH, McClafferty H, Hammond MS, Huibant JM, Ruth P, Knaus HG, Shipston MJ. Functionally diverse complement of large conductance calcium- and voltage-activated potassium channel (BK) alpha-subunits generated from a single site of splicing. J Biol Chem 2005;280:33599-33609. [PubMed: 16081418]

Du W, Bautista JF, Yang H, Diez-Sampedro A, You SA, Wang L, Kotagal P, Luders HO, Shi J, Cui J, Richerson GB, Wang QK. Calcium-sensitive potassium channelopathy in human epilepsy and paroxysmal movement disorder. Nat Genet 2005;37:733-738. [PubMed: 15937479]

Empson RM, Jefferys JG. Ca(2+) entry through L-type $\mathrm{Ca}(2+)$ channels helps terminate epileptiform activity by activation of a $\mathrm{Ca}(2+)$ dependent afterhyperpolarisation in hippocampal CA3. Neuroscience 2001;102:297-306. [PubMed: 11166116]

Ermolinsky B, Arshadmansab MF, Pacheco Otalora LF, Zarei MM, Garrido-Sanabria ER. Deficit of Kcnma1 mRNA expression in the dentate gyrus of epileptic rats. Neuroreport 2008a;19:12911294. [PubMed: 18695509]

Ermolinsky B, Pacheco Otalora LF, Arshadmansab MF, Zarei MM, Garrido-Sanabria ER. Differential changes in mGlu2 and mGlu3 gene expression following pilocarpine-induced status epilepticus: a comparative real-time PCR analysis. Brain Res 2008b;1226:173-180. [PubMed: 18585369]

Erxleben C, Everhart AL, Romeo C, Florance H, Bauer MB, Alcorta DA, Rossie S, Shipston MJ, Armstrong DL. Interacting effects of N-terminal variation and strex exon splicing on slo potassium channel regulation by calcium, phosphorylation, and oxidation. J Biol Chem 2002;277:2704527052. [PubMed: 12016222] 
Fuchs E, Flugge G. Stress, glucocorticoids and structural plasticity of the hippocampus. Neurosci Biobehav Rev 1998;23:295-300. [PubMed: 9884123]

Fuchs E, Flugge G, Ohl F, Lucassen P, Vollmann-Honsdorf GK, Michaelis T. Psychosocial stress, glucocorticoids, and structural alterations in the tree shrew hippocampus. Physiol Behav 2001;73:285-291. [PubMed: 11438353]

Garrido-Sanabria ER, Otalora LF, Arshadmansab MF, Herrera B, Francisco S, Ermolinsky BS. Impaired expression and function of group II metabotropic glutamate receptors in pilocarpinetreated chronically epileptic rats. Brain Res 2008;1240:165-176. [PubMed: 18804094]

Gu N, Vervaeke K, Storm JF. BK potassium channels facilitate high-frequency firing and cause early spike frequency adaptation in rat CA1 hippocampal pyramidal cells. J Physiol 2007;580:859-882. [PubMed: 17303637]

Hu H, Shao LR, Chavoshy S, Gu N, Trieb M, Behrens R, Laake P, Pongs O, Knaus HG, Ottersen OP, Storm JF. Presynaptic Ca2+-activated $\mathrm{K}+$ channels in glutamatergic hippocampal terminals and their role in spike repolarization and regulation of transmitter release. J Neurosci 2001;21:95859597. [PubMed: 11739569]

Huang GJ, Herbert J. Stimulation of neurogenesis in the hippocampus of the adult rat by fluoxetine requires rhythmic change in corticosterone. Biol Psychiatry 2006;59:619-624. [PubMed: 16325782]

Joels M. Role of corticosteroid hormones in the dentate gyrus. Prog Brain Res 2007;163:355-370. [PubMed: 17765729]

Kaczorowski GJ, Knaus HG, Leonard RJ, McManus OB, Garcia ML. High-conductance calciumactivated potassium channels; structure, pharmacology, and function. J Bioenerg Biomembr 1996;28:255-267. [PubMed: 8807400]

Knaus HG, Schwarzer C, Koch RO, Eberhart A, Kaczorowski GJ, Glossmann H, Wunder F, Pongs O, Garcia ML, Sperk G. Distribution of high-conductance $\mathrm{Ca}(2+)$-activated $\mathrm{K}+$ channels in rat brain: targeting to axons and nerve terminals. J Neurosci 1996;16:955-963. [PubMed: 8558264]

Lai GJ, McCobb DP. Opposing actions of adrenal androgens and glucocorticoids on alternative splicing of Slo potassium channels in bovine chromaffin cells. Proc Natl Acad Sci U S A 2002;99:7722-7727. [PubMed: 12032350]

Lai GJ, McCobb DP. Regulation of alternative splicing of Slo K+ channels in adrenal and pituitary during the stress-hyporesponsive period of rat development. Endocrinology 2006;147:3961-3967. [PubMed: 16675526]

Latorre R, Brauchi S. Large conductance Ca2+-activated K+ (BK) channel: activation by $\mathrm{Ca} 2+$ and voltage. Biol Res 2006;39:385-401. [PubMed: 17106573]

Latorre R, Oberhauser A, Labarca P, Alvarez O. Varieties of calcium-activated potassium channels. Annu Rev Physiol 1989;51:385-399. [PubMed: 2653189]

Lovell PV, King JT, McCobb DP. Acute modulation of adrenal chromaffin cell BK channel gating and cell excitability by glucocorticoids. J Neurophysiol 2004;91:561-570. [PubMed: 12904339]

Lu R, Alioua A, Kumar Y, Eghbali M, Stefani E, Toro L. MaxiK channel partners: physiological impact. J Physiol 2006;570:65-72. [PubMed: 16239267]

MacDonald SH, Ruth P, Knaus HG, Shipston MJ. Increased large conductance calcium-activated potassium (BK) channel expression accompanied by STREX variant downregulation in the developing mouse CNS. BMC Dev Biol 2006;6:37. [PubMed: 16872513]

Mahmoud SF, McCobb DP. Regulation of Slo potassium channel alternative splicing in the pituitary by gonadal testosterone. J Neuroendocrinol 2004;16:237-243. [PubMed: 15049854]

Martin ED, Araque A, Buno W. Synaptic regulation of the slow Ca2+-activated K+ current in hippocampal CA1 pyramidal neurons: implication in epileptogenesis. J Neurophysiol 2001;86:2878-2886. [PubMed: 11731544]

Mazarati AM, Pineda E, Shin D, Tio D, Taylor AN, Sankar R. Comorbidity between epilepsy and depression: Role of hippocampal interleukin-1beta. Neurobiol Dis. 2009a

Mazarati AM, Shin D, Kwon YS, Bragin A, Pineda E, Tio D, Taylor AN, Sankar R. Elevated plasma corticosterone level and depressive behavior in experimental temporal lobe epilepsy. Neurobiol Dis 2009b;34:457-461. [PubMed: 19285131] 
McCartney CE, McClafferty H, Huibant JM, Rowan EG, Shipston MJ, Rowe IC. A cysteine-rich motif confers hypoxia sensitivity to mammalian large conductance voltage- and Ca-activated $\mathrm{K}(\mathrm{BK})$ channel alpha-subunits. Proc Natl Acad Sci U S A 2005;102:17870-17876. [PubMed: 16306267]

McCobb DP, Hara Y, Lai GJ, Mahmoud SF, Flugge G. Subordination stress alters alternative splicing of the Slo gene in tree shrew adrenals. Horm Behav 2003;43:180-186. [PubMed: 12614648]

McEwen BS. Effects of adverse experiences for brain structure and function. Biol Psychiatry 2000;48:721-731. [PubMed: 11063969]

McEwen BS. Plasticity of the hippocampus: adaptation to chronic stress and allostatic load. Ann N Y Acad Sci 2001;933:265-277. [PubMed: 12000027]

McManus OB. Calcium-activated potassium channels: regulation by calcium. J Bioenerg Biomembr 1991;23:537-560. [PubMed: 1917908]

Mirescu C, Gould E. Stress and adult neurogenesis. Hippocampus 2006;16:233-238. [PubMed: 16411244]

Montaron MF, Piazza PV, Aurousseau C, Urani A, Le Moal M, Abrous DN. Implication of corticosteroid receptors in the regulation of hippocampal structural plasticity. Eur J Neurosci 2003;18:3105-3111. [PubMed: 14656306]

Nardi A, Olesen SP. BK channel modulators: a comprehensive overview. Curr Med Chem 2008;15:1126-1146. [PubMed: 18473808]

Ormerod BK, Lee TT, Galea LA. Estradiol initially enhances but subsequently suppresses (via adrenal steroids) granule cell proliferation in the dentate gyrus of adult female rats. J Neurobiol 2003;55:247-260. [PubMed: 12672021]

Pacheco Otalora LF, Hernandez EF, Arshadmansab MF, Francisco S, Willis M, Ermolinsky B, Zarei M, Knaus HG, Garrido-Sanabria ER. Down-regulation of BK channel expression in the pilocarpine model of temporal lobe epilepsy. Brain Res 2008;1200:116-131. [PubMed: 18295190]

Petrik D, Brenner R. Regulation of STREX exon large conductance, calcium-activated potassium channels by the beta4 accessory subunit. Neuroscience 2007;149:789-803. [PubMed: 17945424]

Pfaffl MW. A new mathematical model for relative quantification in real-time RT-PCR. Nucleic Acids Res 2001;29:45.

Qin Y, Karst H, Joels M. Chronic unpredictable stress alters gene expression in rat single dentate granule cells. J Neurochem 2004;89:364-374. [PubMed: 15056280]

Racine RJ. Modification of seizure activity by electrical stimulation II. Motor seizure. Electroencephalogr Clin Neurophysiol 1972;32:281-294. [PubMed: 4110397]

Radley JJ, Morrison JH. Repeated stress and structural plasticity in the brain. Ageing Res Rev 2005;4:271-287. [PubMed: 15993654]

Sah P, Faber ES. Channels underlying neuronal calcium-activated potassium currents. Prog Neurobiol 2002;66:345-353. [PubMed: 12015199]

Saito M, Nelson C, Salkoff L, Lingle CJ. A cysteine-rich domain defined by a novel exon in a slo variant in rat adrenal chromaffin cells and PC12 cells. J Biol Chem 1997;272:11710-11717. [PubMed: 9115223]

Shanley LJ, O'Malley D, Irving AJ, Ashford ML, Harvey J. Leptin inhibits epileptiform-like activity in rat hippocampal neurones via PI 3-kinase-driven activation of BK channels. J Physiol 2002;545:933-944. [PubMed: 12482897]

Sheehan JJ, Benedetti BL, Barth AL. Anticonvulsant effects of the BK-channel antagonist paxilline. Epilepsia 2009;50:711-720. [PubMed: 19054419]

Shipston MJ, Duncan RR, Clark AG, Antoni FA, Tian L. Molecular components of large conductance calcium-activated potassium (BK) channels in mouse pituitary corticotropes. Mol Endocrinol 1999;13:1728-1737. [PubMed: 10517674]

Shruti S, Clem RL, Barth AL. A seizure-induced gain-of-function in BK channels is associated with elevated firing activity in neocortical pyramidal neurons. Neurobiol Dis 2008;30:323-330. [PubMed: 18387812]

Stocker M, Hirzel K, D'Hoedt D, Pedarzani P. Matching molecules to function: neuronal Ca2+activated $\mathrm{K}+$ channels and afterhyperpolarizations. Toxicon 2004;43:933-949. [PubMed: 15208027] 
Takahashi LK. Glucocorticoids and the hippocampus. Developmental interactions facilitating the expression of behavioral inhibition. Mol Neurobiol 1996;13:213-226. [PubMed: 8989771]

Tian L, Coghill LS, MacDonald SH, Armstrong DL, Shipston MJ. Leucine zipper domain targets cAMP-dependent protein kinase to mammalian BK channels. J Biol Chem 2003;278:8669-8677. [PubMed: 12509433]

Tian L, Duncan RR, Hammond MS, Coghill LS, Wen H, Rusinova R, Clark AG, Levitan IB, Shipston MJ. Alternative splicing switches potassium channel sensitivity to protein phosphorylation. J Biol Chem 2001a;276:7717-7720. [PubMed: 11244090]

Tian L, Hammond MS, Florance H, Antoni FA, Shipston MJ. Alternative splicing determines sensitivity of murine calcium-activated potassium channels to glucocorticoids. J Physiol 2001b; 537:57-68. [PubMed: 11711561]

Turski WA, Cavalheiro EA, Bortolotto ZA, Mello LM, Schwarz M, Turski L. Seizures produced by pilocarpine in mice: a behavioral, electroencephalographic and morphological analysis. Brain Res 1984;321:237-253. [PubMed: 6498517]

Turski WA, Cavalheiro EA, Schwarz M, Czuczwar SJ, Kleinrok Z, Turski L. Limbic seizures produced by pilocarpine in rats: behavioural, electroencephalographic and neuropathological study. Behav Brain Res 1983;9:315-335. [PubMed: 6639740]

Wang B, Rothberg BS, Brenner R. Mechanism of increased BK channel activation from a channel mutation that causes epilepsy. J Gen Physiol 2009;133:283-294. [PubMed: 19204188]

Weiger TM, Hermann A, Levitan IB. Modulation of calcium-activated potassium channels. J Comp Physiol A Neuroethol Sens Neural Behav Physiol 2002;188:79-87. [PubMed: 11919690]

Xie J, Black DL. A CaMK IV responsive RNA element mediates depolarization-induced alternative splicing of ion channels. Nature 2001;410:936-939. [PubMed: 11309619]

Xie J, McCobb DP. Control of alternative splicing of potassium channels by stress hormones. Science 1998;280:443-446. [PubMed: 9545224]

Zhu N, Eghbali M, Helguera G, Song M, Stefani E, Toro L. Alternative splicing of Slo channel gene programmed by estrogen, progesterone and pregnancy. FEBS Lett 2005;579:4856-4860.

[PubMed: 16102753] 
A

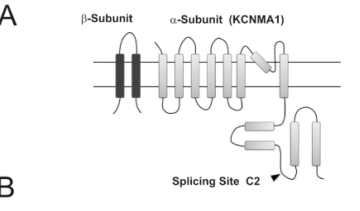

zero

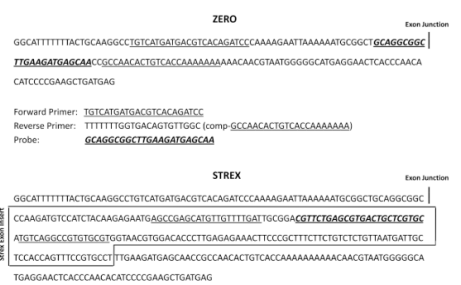

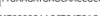

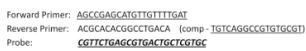

Figure 1.

A. Diagram representation of Kcnmal splicing at site C2 and generation of TaqMan probes for qPCR. B. Sequence of primers and probes for TaqMan Assays used in the detection of ZERO and STREX splice variants (174 bp insert). The primers are underlined and the probe underlined and highlighted. 

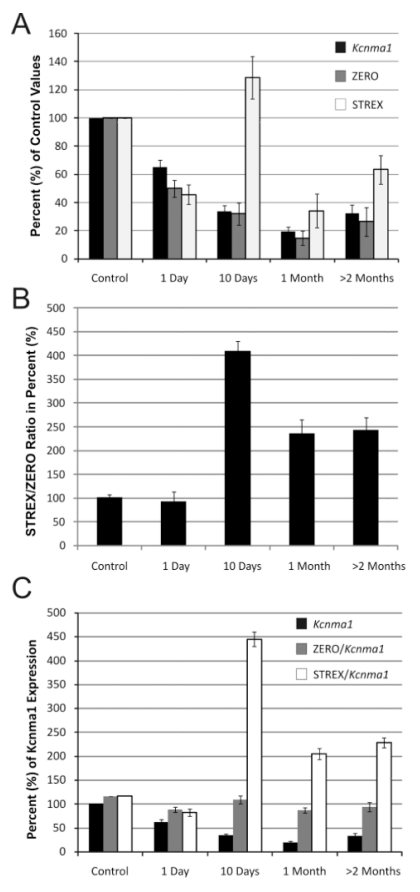

Figure 2.

A. Down-regulation of main transcript Kcnmal is associated with a relative increase in STREX variant after 10 days following pilocarpine-induced status epilepticus (SE). A. Graphic representation of the time course of relative changes in gene expression normalized to control levels for Kcnmal transcripts and spliced variants STREX and ZERO at different periods following SE induction. B. Proportional changes on STREX/ZERO in different experimental groups indicating a robust up-regulation of STREX transcripts relative to ZERO after 10 days following SE. C. Relative changes on the expression of Kcnmal main transcript compared to control levels (black bars) and time course of proportional changes on STREX (STREX/Kcnmal ratio) and ZERO (ZERO/Kcnmal ratio) versus Kcnmal expression at different periods following SE. 
Table 1

TaqMan probes and primers to qPCR of Kcnmal splice variant STREX and ZERO.

\begin{tabular}{cccc}
\hline STREX & Tm & \%GC \\
\hline Probe & CGTTCTGAGCGTGACTGCTCGTGC & 69.2 & 43 \\
Primer Forward & AGCCGAGCATGTTGTTTTGAT & 58.3 & 65 \\
Primer Reverse & ACGCACACGGCCTGACA & 59.4 & 63 \\
Amplicon Size & $69 \mathrm{bp}$ & & \\
\hline ZERO & & & \\
\hline \multirow{2}{*}{ Probe } & GCAGGCGGCTTGAAGATGAGCAA & 62.5 & \multirow{2}{*}{57} \\
Primer Forward & TGTCATGATGACGTCACAGATCC & 56.6 & 48 \\
Primer Reverse & TTTTTTTGGTGACAGTGTTGGC & 54.8 & 41 \\
Amplicon Size & 92 bp & & \\
\hline
\end{tabular}

Bp: Base pairs Tm: Melting temperature 


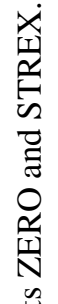

茌

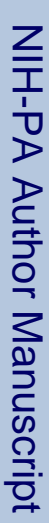

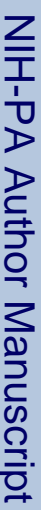

\begin{tabular}{|c|c|c|c|c|c|c|}
\hline$\therefore$ & $\nsubseteq$ & $\begin{array}{l}\dot{s} \\
\dot{g}\end{array}$ & $\begin{array}{l}n \\
0 \\
0 \\
0\end{array}$ & $\overrightarrow{\dot{f}}$ & ભై & 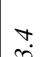 \\
\hline$\approx$ & 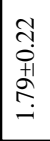 & 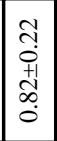 & 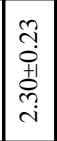 & $\begin{array}{l}\infty \\
\stackrel{\infty}{0} \\
\dot{+1} \\
\vdots 0 \\
0\end{array}$ & 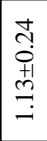 & $\begin{array}{l}2 \\
0 \\
0 \\
\dot{0} \\
2\end{array}$ \\
\hline$\therefore$ & \& & in & $\frac{\vec{m}}{m}$ & $\stackrel{\check{\Xi}}{\dot{\Xi}}$ & 苞 & $\hat{\imath}$ \\
\hline$\approx$ & $\begin{array}{l}0 \\
0 \\
0 \\
+1 \\
\stackrel{1}{0} \\
\stackrel{-}{-}\end{array}$ & \begin{tabular}{|c|c}
0 \\
0 \\
0 \\
0 \\
$\infty$ \\
$\infty$ \\
0 \\
0
\end{tabular} & $\mid \begin{array}{l}0 \\
0 \\
0 \\
0 \\
0 \\
0 \\
0 \\
0\end{array}$ & 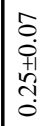 & $\begin{array}{l}\text { o } \\
0 \\
0 \\
011 \\
01 \\
0 \\
0\end{array}$ & $\mid \begin{array}{l}\dot{8} \\
\dot{\dot{\theta}} \\
\dot{Q}\end{array}$ \\
\hline$\Delta^{\circ}$ & 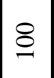 & 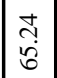 & $\begin{array}{l}\tilde{\sigma} \\
\tilde{\rho}\end{array}$ & $\mid \begin{array}{l}0 \\
\stackrel{2}{2} \\
=\end{array}$ & $\begin{array}{l}\text { ñ } \\
\text { mij }\end{array}$ & $\hat{\text { in }}$ \\
\hline$\stackrel{2}{\approx}$ & 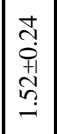 & 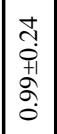 & 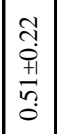 & $\mid \begin{array}{l}\tilde{c} \\
\tilde{y} \\
\hat{y} \\
\hat{\alpha} \\
0\end{array}$ & 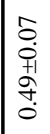 & $\begin{array}{l}\overrightarrow{8} \\
\dot{0} \\
\dot{0} \\
\end{array}$ \\
\hline & Ë & 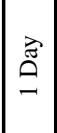 & $\begin{array}{l}\vec{\Xi} \\
\text { Oे } \\
\varrho\end{array}$ & 竧 & 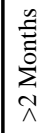 & 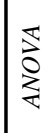 \\
\hline
\end{tabular}

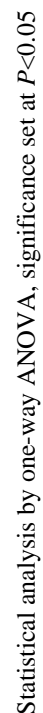

